\title{
The electricity valuation in fuel and energy balance of Sakha Republic (Yakutia)
}

\author{
Albina Ivanova, and Tatiana Petrova*, Larionov Institute of Physical and Engineering \\ Problems of the North of Siberian Branch of the Russian Academy of Sciences, Yakutsk, \\ Russia
}

\begin{abstract}
In Sakha Republic (Yakutia), there is a tendency to increase the cost of fuel in the Power station generation. In the cost of electricity power generation on a decentralized territory, the main part of the costs falls on the fuel component. The greatest difference in the natural and value terms of consumption is in the diesel fuel. Consumption of diesel fuel at the Power station is much lower, but in terms of the value consumption structure has the largest percentage. At the same time, the valuation increases year by year. This is mainly due to the use expansion of diesel power generation in industrial facilities of the Fuel and Extractive industries. Keywords: electricity power, fuel and energy balance (FEB), final power consumption, electricity tariffs, costs.
\end{abstract}

One of the indicators of successful socio-economic development of the economy is an increase in electricity consumption. At the same time, the key issue remains the cost of the fuel component of production, which ultimately affects the tariffs formation for the population and the economy sectors. In Sakha Republic (Yakutia), the issue of price formation is of a territorial nature, or, zonal distribution. It is connected with the territorial dispersion of the region. At present, in the Republic there are essentially four zones of electricity consumption, where tariffs vary and, in most of which, are regulated by the government. Firstly, it is a centralized Yakut power system of isolated territories in the Central and Western energy sectors of the Republic, in which the guaranteeing electricity supplier is PJSC Yakutskenergo. Secondly, the decentralized remote zone of the northern and local territories, which is serviced by JSC Sakhaenergo. Third, technologically isolated power systems of private industrial companies. And fourthly, the zone of operation of the Far Eastern wholesale electricity market, which also covers the South Yakut energy sector.

This article is based on a valuation of the electricity prices formation, which makes it possible to measure the amount of financial costs and results for all energy flows. With its help, the economic rationality of the FEB structure. Also, the work carried out a valuation of losses on each energy balance chain with options for implementing measures aimed at reducing them. The study of the dynamics of the FEB valuation allows us to analyze trends in the changes in the structure of fuel prices and electricity tariffs, as well as identify the main components. $[1,2,3]$

For ease of evaluation, the coverage of the years is from 2010 to 2016, the period of the greatest increase in fuel prices. The cost estimate was carried out taking into account the

*Corresponding author: tn_petrova_s@mail.ru 
current state of development of the Republic's electric power industry based on the following electric balance blocks.

\section{The Electric Balance Blocks}

\subsection{The Electricity Generation and the Flows}

The generation of electricity by the stations of the centralized Yakut power system increases insignificantly. The average annual growth rate from 2012 to 2016 is $102 \%$. At the same time, the generation of electricity by technologically isolated sources increased by $46 \%$, as a result of the increase in the decentralized zone of generating power sources associated with oil production and transportation. Thus, the total power generation during the period increased by $10.3 \%$.

The electricity flows connect the South Yakut energy sector with the Amur energy system, the West with the Irkutsk energy system, the East with the Magadan energy system, and the North with the Chaun-Bilibino energy center.

The South Yakut energy sector, which used to be located in the zone of the guaranteeing electricity supplier PJSC Yakutskenergo, is included in the capacity and non-price zone of the wholesale electricity market of the Far East. Preparatory work is underway to enter the specified market of the Central and Western energy sectors. The total amount of electricity delivered to the IPS of the East from the South Yakut energy sector was around 9 billion $\mathrm{kWh}$. From the Chukotka and Magadan power systems, around 1 billion $\mathrm{kWh}$ have been received for the whole period.

\subsection{The Electricity consumption in the processes of transformation, transmission and distribution of energy resources}

Power generation by the thermal power stations consumes from 365 to 410 gee per 1 $\mathrm{kWh}$. At the diesel power stations, the specific consumption of diesel fuel differs by a factor of 1.5 and varies from 412 to 630 gee per $1 \mathrm{kWh}$.

The percentage of losses in power grid averages $12 \%$ of the electricity supplied to the grid. During the period under review, they grew by $3.7 \%$.

The percentage of electric power consumption for own needs averages $5.6 \%$ of the total output. Electricity consumption for own needs during the period under review tended to decrease. The average annual rate of decline was $102.9 \%$.

\subsection{The Final power consumption}

As of 2016, the main place in the structure of electricity consumption in the Republic is the Mining - 33.6\%. Then, transport and communications account for $15.3 \%$ and power and energy production $-14.9 \%$. The power consumption percentage of the population is $11.4 \%$. The percentage of electricity losses in power grid is more than the consumption of the population and is $12.4 \%$ (Fig. 1).

Most of the increase in electricity consumption is also associated with an increase in the electricity generation from local decentralized energy sources of industrial oil production and oil pipeline ESPO. 


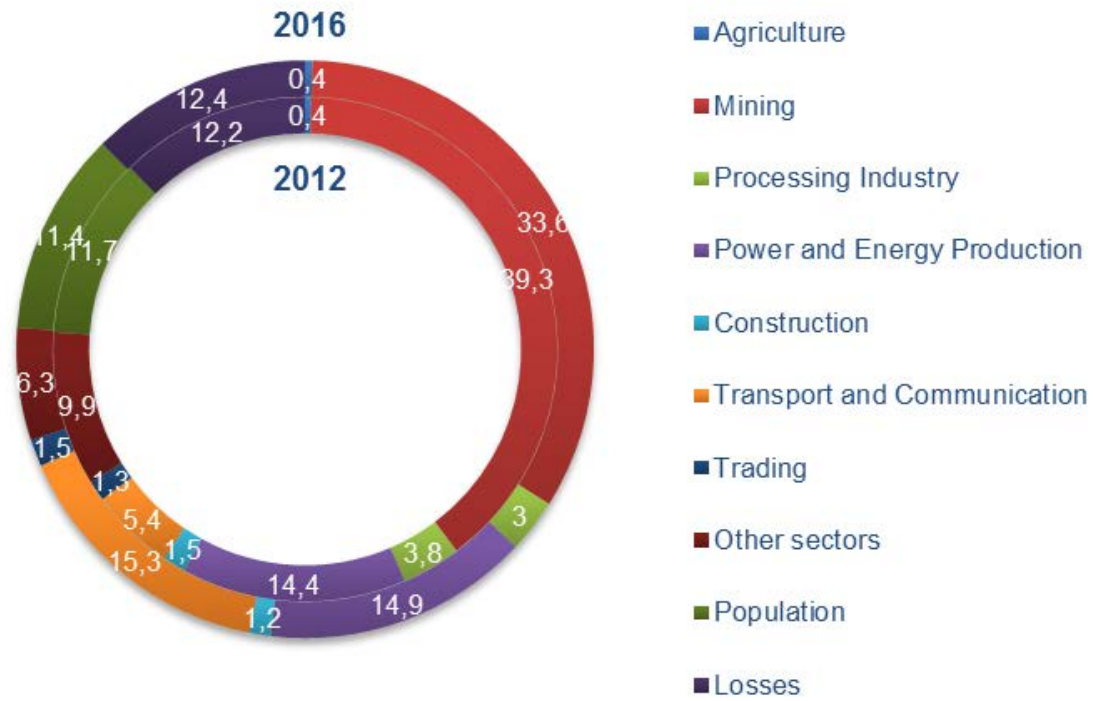

Fig. 1. The Structure of electricity consumption in 2012 and 2016, \%

\section{The Valuation of the electricity balance}

The value calculation was carried out taking into account the objective factors of production and economic activity of the electric power industry enterprises of the Republic, as well as the current dynamics of regulated electricity tariffs by consumer categories.

\subsection{The structure of fuel consumption for electricity generation in physical and value terms}

Taking into account electricity flows both in and out of the Republic, without taking into account the costs of processing industrial enterprises by technologically isolated power stations, the balance costs for the production, transmission and sale of electricity account for more than 30 billion rubles per annum.

In the value of generating electricity, the percentage of the fuel component is high. For example, in the decentralized zone of the northern regions it occupies a large half and is around $60 \%$. Here, the main fuel for electricity generation is diesel fuel, the costs of acquiring and delivering it are growing every year. Annually for the electricity generation in the decentralized zone of the northern regions it is imported from the outside and around 70 thousand tons of diesel fuel is delivered.

The value percentage of diesel fuel in the consumption structure tends to increase. The expensive cost of diesel fuel greatly affects the value of generation from diesel power stations. For example, the average unit cost of diesel power stations of JSC Sakhaenergo in 2016 on average is 27.38 rubles per $1 \mathrm{kWh}$. The measures taken to replace expensive diesel fuel for alternative types of energy supply make it possible to cut expenses for the purchase and delivery of diesel fuel. So, for the last 5 years, the introduction of the solar power plants in the territory of isolated territories has allowed to generate 1.334 million $\mathrm{kWh}$ of electricity and saved $4 \mathrm{~kg}$ of diesel fuel in terms of generating $1 \mathrm{kWh}$ of solar energy. The total savings amounted to 290 million rubles.

Let's compare the physical and value structure of fuel consumption for electricity generation in the territory of the Republic (Fig. 2). 


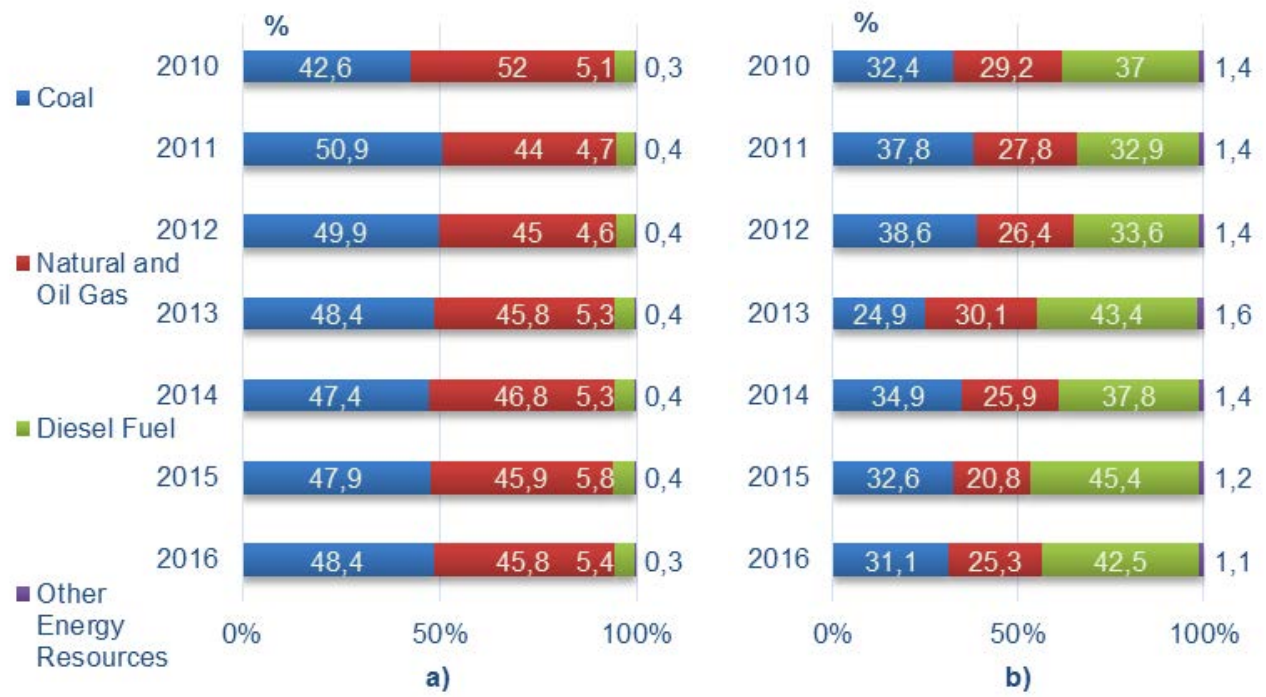

Fig. 2. Comparison of the structure of fuel consumption for the electricity generation in power stations of Sakha Republic in physical (a) and value (b) terms

In the overall structure of fuel consumption for electricity generation in power stations, coal and gas dominate in physical terms. But part b of Fig. 2 clearly shows that the meager percentage of diesel fuel in the structure of energy consumption for the production of electricity in the Republic in physical terms by the end of the period began to occupy almost half of consumption in value terms. This led to a high rise in prices for diesel fuel. This, as was said above, is connected with importation from outside and transportation to remote northern regions. Also, the rate of increase in gas prices relative to other types of energy resources is increasing. The average growth rate is $12 \%$.

\subsection{The Specific fuel consumption}

Specific fuel consumption of power stations is still high compared to the average Russian national average. This is due, first of all, to severe climatic conditions of exploitation, which is exacerbated by high physical and moral depreciation of power station equipment. If in 2010 the average specific fuel consumption at thermal power stations was 215.6 gce per $1 \mathrm{kWh}$, then by 2016 it increased to 233.3 gce per $1 \mathrm{kWh}$. In terms of value, the specific fuel consumption in 2010 amounted to 1.5 rubles, and in $2016-3.17$ rubles per $1 \mathrm{kWh}$. Growth in physical terms is $8 \%$, in value terms -2.11 times. In the total value of electricity production, the percentage of the fuel component outstrips the growth of other items of production costs in some cases 1.5 times. Losses in power grid also affect the growth of the cost price.

Annual electricity losses in power grid of different levels are estimated at 2 billion rubles. This is explained by the large length of power grid not only near populated areas and developed infrastructure, but also in remote places where it is very difficult to update them, which leads to another problem as high wear. 


\subsection{The structure of the final power consumption's valuation}

Electricity tariffs as in other regions of the Far East are higher than average Russian. The ceiling tariff set by the State Committee for Pricing Policy of Sakha Republic (Yakutia), for electricity from the guaranteeing supplier of PJSC Yakutskenergo for industrial consumers in 2016 is 7.8 rubles per $1 \mathrm{kWh}$. From the structure of the value estimate of the final electricity consumption (Fig. 3), it can be revealed that the compensation of more than half of the costs of generating companies falls on industry $(49.3 \%)$, the high value of which is a consequence of cross-subsidizing tariffs between the population and industrial enterprises. The percentage of services in 2016 , it was $15.5 \%$, the population $-12.9 \%$. The value structure has changed significantly due to increased electricity consumption by transport and communications. In 2016, the percentage rose to $20.3 \%$, compared with $4.8 \%$ in 2010 . Thus, increased energy costs for industrial enterprises do not allow for extended investment activities, increasing the value of finished products.

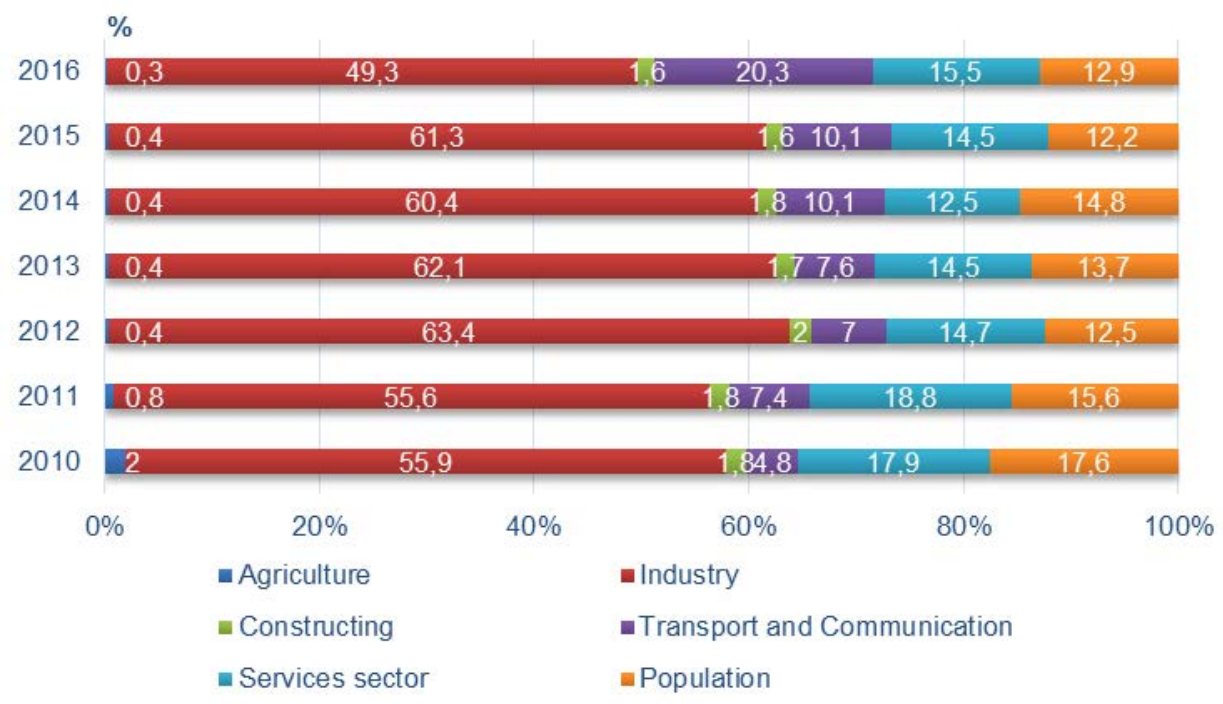

Fig. 3. The structure of the final power consumption's valuation in Sakha Republic

The aforementioned factors can be confirmed by the given indicators of the Republic statistics. The indices of the prices of production and consumption of electric power exceed the purchasing power of the population by an average of 12 percentage points. Over the period, the average price index of electricity producers amounted to $112.3 \%$, consumption $111.5 \%$, purchasing power $-100.1 \%$ (Fig. 4). This means that the price of electricity production for the period grew at an average rate of $0.09 \%$, consumption $-0.59 \%$, therefore, the purchasing power of the population declined by $0.96 \%$

The further increase in fuel prices, namely, diesel, will lead to high expenses for electricity generation, as a result of which accelerated tariff growth is possible both for industrial consumers and for the population. 


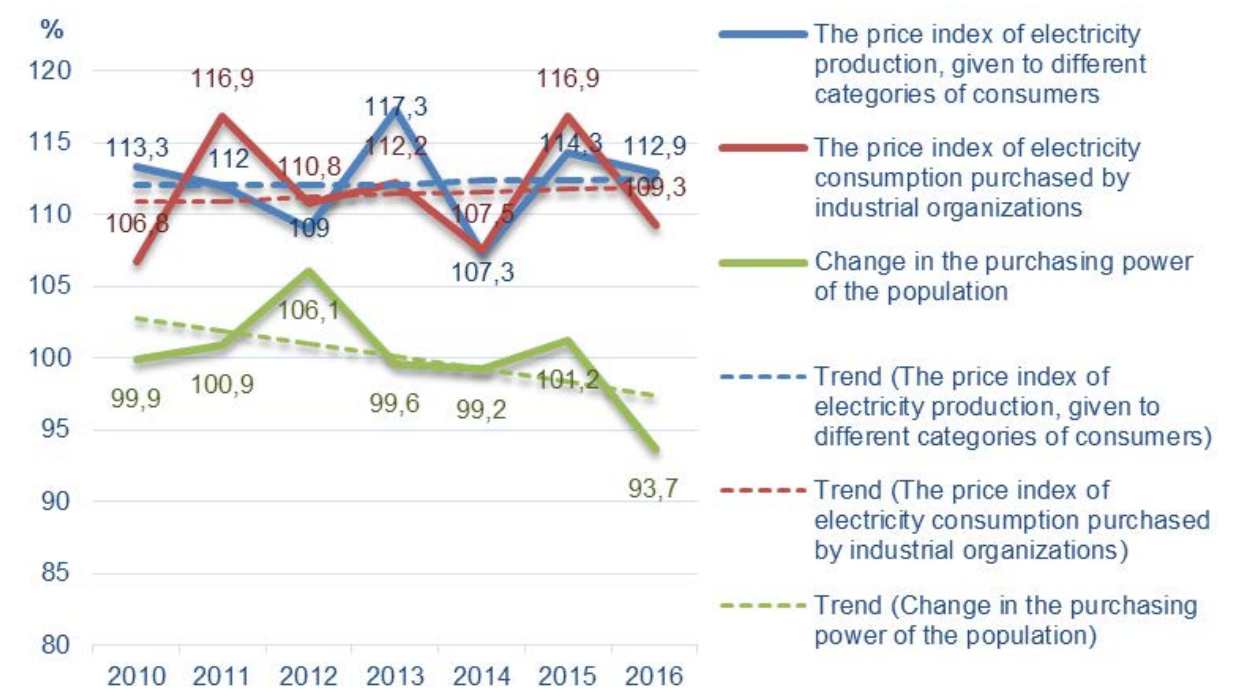

Fig. 4. Dynamics of indices of prices for production, consumption and purchasing power of the population in Sakha Republic (Yakutia)

\subsection{The effect of changes in diesel fuel prices on total electricity production costs}

The forecast was fulfilled before 2022 for energy sectors of the Republic, except for the action zone of the wholesale electricity market. The analysis is based on the change in prices for diesel fuel, which is the most influential in the value structure of fuel consumption for generating electricity.

The growth rate of diesel fuel in the Northern energy area amounted to $113.2 \%$, on the Central $-110.6 \%$, on the Western $-108.6 \%$. Based on a retrospective analysis of growth rates for diesel generation, a forecast for diesel fuel prices was compiled. Given the growth rate and the existing scheme for importing fuel, taking into account inflationary processes in the economy, the price of diesel fuel for the Northern regions may increase by 2.1 times in 2022 compared with the level of 2016 , in the Central power sector by $83 \%$, in the Western - by $64 \%$. The increase in the price of diesel fuel will lead to an increase in costs for the fuel component of power stations by $54 \%$. The total costs of power stations for electricity generation will grow by $0.24 \%$, with a rise in the value of diesel fuel by $1 \%$, by $1.37 \%$ with a rise in price by $5 \%$, and by $3.3 \%$ with a rise in price by $10 \%$ (Fig. 5).

Since 2017, a law has been introduced on the mechanism for equalizing electricity tariffs for the Far Eastern regions of the Russian Federation with an average Russian level. According to this law, the revenue received from energy generating companies is compensated for at the expense of the difference in the addition of the wholesale electricity market price zones to the price of the wholesale electricity market in the European, Ural and Siberian parts of the Russian Federation. For the Republic, this amount is more than half of the cost of electricity production, i.e., in 2017 this amount was 15.2 billion rubles. As a result, the expenses of energy companies are covered and cross-subsidization problems between industrial companies and the social sphere, together with expensive diesel generation, subsidized earlier from the state budget. 


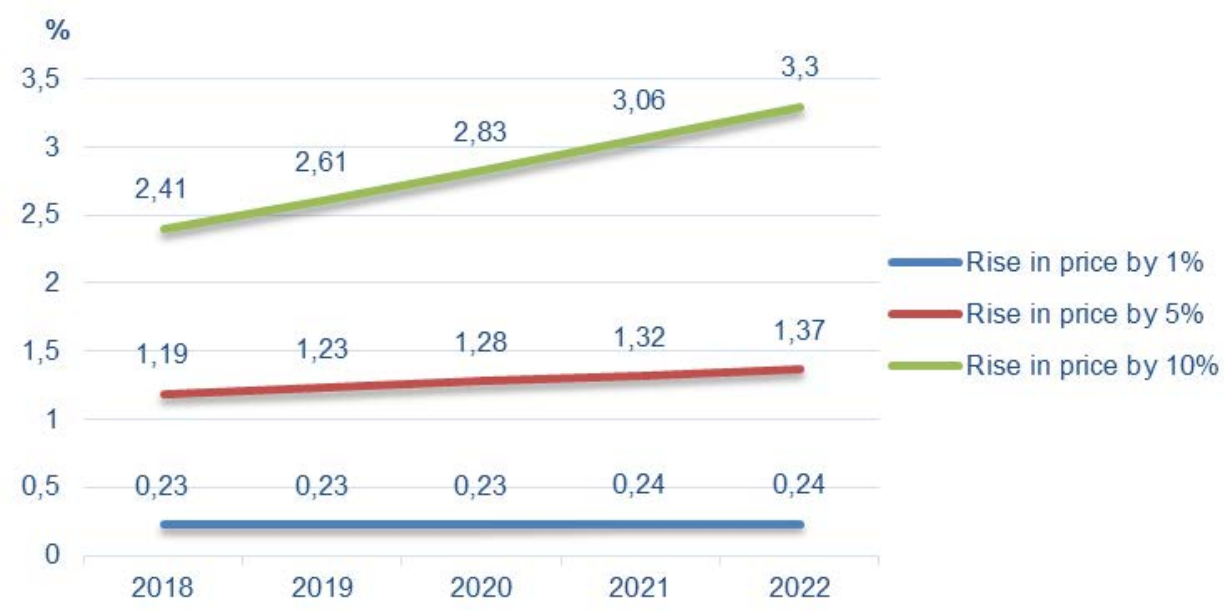

Fig. 5. The forecast of increasing the total costs rate of the power stations for the electricity generation from the rise in price of diesel fuel.

At the same time, the tendency of the rise in price of diesel fuel, as well as other costs of generating companies for electricity generation, marks an annual increase in the amount of the crossroads on the above mechanism. As a result, tariffs for other industrial consumers by 2022 may exceed 9.35 rubles per $1 \mathrm{kWh}$.

For the population, a single-rate tariff can reach 6.81 rubles per $1 \mathrm{kWh}$. At the same time, the purchasing power of the population may drop to the level of $94.3 \%$.

\section{Conclusions}

The change in the cost of generating electricity from diesel power staions is very sensitive to changes in the price of diesel fuel. From the forecasted price of diesel fuel, it was obtained that a $1 \%$ price increase would lead to an increase in electricity generation costs by an average of $0.23 \%$. The further rise in prices for diesel fuel with an average growth rate of $10 \%$ will lead to an increase in all energy production costs by at least $3.3 \%$. By 2022, with an increase in other costs for the production and transmission of electricity, tariffs for the population may increase by $20-25 \%$.

Thus, further growth of tariffs for the population can lead to a decrease in the purchasing power of the population by 2022 by $6 \%$ compared to the level of 2016 .

To reduce the value of the fuel component of electricity production, it is necessary to ensure more rational use of fuel and energy resources. One of the ways to improve the efficiency of electricity supply in the North could be the introduction of intellectualization elements in the electric power system, the use of more modern autonomous generation technologies for electricity generation, and the expansion of the use of alternative renewable and other types of energy.

\section{References}

1. Methods and models of development of regional energy programs. Edited by B.G. Saneev. Novosibirsk, 140 p. (2003) (in Russian)

2. Lyubimova E.V., Suslov N.I., Churashev V.N. et.ol. Methodology and practice of construction and use of regional fuel and energy balances. Novosibirsk: Izd. IEEPP SB RAS, 452 p. (2010) (in Russian) 
3. Sharina V.G. Cost estimation of energy efficiency of the regional economy (on the example of Sakha Republic (Yakutia)). Science and education. No 1. pp. 24-27 (2007) (in Russian)

4. Petrov N.A. Concept and methodical aspects of formation of Sakha (Yakutia) republic fuel-energy balance for the period up to 2005. Energy of the North-East: state, problems and development (collection of papers and scientific articles). Yakuysk. pp. 75-95 (2004) (in Russian)

5. Borisova I.N., Voronina S.A., Kretinina Yu.S., Nekrasov A.S. Valuation of Russia's Energy Balance. Problems of Forecasting, No 4, pp. 65-74 (2002) (in Russian)

6. Nekrasov A.S., Voronina S.A., Borisova I.N., Kretinina Yu.S. Valuation of the energy balance of Russia. Open seminar "Economic problems of the energy complex" Thirty-third session of June 24, 2002 / Seminar leader Professor, Doctor of Economic Sciences A.S. Nekrasov. Moscow (2005) (in Russian)

7. Saneev B.G., Sokolov A.D., Muzychuk S.Yu., Muzychuk R.I. Fuel and energy balances in the system of comprehensive research of the development of regional fuel and energy complex. Proceedings of the Russian Academy of Sciences. Power Engineering, No 2, pp. 21-35 (2011) (in Russian)

8. Sokolov A.D., Muzychuk S. Yu., Muzychuk R.I. Fuel and energy balance of the Irkutsk region in physical and value terms: development methods and main results of researches. IGEA news, No 1, pp. 124-129 (2013) (in Russian) 